\title{
Vitamin D Deficiency and Its Response to Supplementation as "Stoss Therapy" in Children with Cyanotic Congenital Heart Disease Undergoing Open Heart Surgery
}

\author{
${ }^{1}$ Department of Cardiothoracic and Vascular Surgery, CN Centre, \\ All India Institute of Medical Sciences, New Delhi, India \\ 2Department of Cardiac Anaesthesiology, CN Centre, All India \\ Institute of Medical Sciences, New Delhi, India \\ ${ }^{3}$ Department of Laboratory Medicine, CN Centre, All India Institute \\ of Medical Sciences, New Delhi, India \\ ${ }^{4}$ Department of Biostatistics, All India Institute of Medical Sciences, \\ New Delhi, India \\ J Card Crit Care TSS 2020;3:17-23
}

Manoj Kumar Sahu ${ }^{1}$ Chalattil Bipin ${ }^{1}$ Harsha Vardhan Niraghatam ${ }^{1}$ Ameya Karanjkar ${ }^{2}$ Sarvesh Pal Singh Palleti Rajashekar ${ }^{1} \quad$ Lakshmy Ramakrishnan ${ }^{3} \quad$ V. Devagourou ${ }^{1} \quad$ Ashish Datt Upadhyay ${ }^{4}$ Shiv Kumar Choudhary ${ }^{1}$

\author{
Address for correspondence Manoj K. Sahu, MD, DNB, Department \\ of Cardiothoracic and Vascular Surgery, CTVS Office, 7th Floor, \\ CN Centre, All India Institute of Medical Sciences, New Delhi 110029, \\ India (e-mail: drmanojsahu@gmail.com).
}

\section{Abstract}

Keywords

- vitamin D deficiency

- stoss therapy

- cardiopulmonary bypass

- tetralogy of Fallot

- undergoing intracardiac repair
Background Data from many studies suggest that patients with congenital heart disease are vitamin $\mathrm{D}$ (vitD) deficient. Following cardiac surgery as a result of intraoperative institution of cardiopulmonary bypass (CPB), serum vitD levels become even low. This may affect postoperative convalescence in terms of mechanical ventilation, inotropic support, infection, and so forth.

Objective We intended to study the prevalence of vitD deficiency pre and post cardiac surgery and the effect of vitD supplementation (stoss therapy) on postoperative convalescence of the children with tetralogy of Fallot (TOF) undergoing intracardiac repair (ICR).

Methodology In this randomized controlled trial (RCT), 60 children younger than 18 years with TOF and serum vitD levels $<20 \mathrm{ng} / \mathrm{dL}$ were randomized into two groups. The study group received vitD supplementation as "stoss therapy" at 10,000 units/kg body weight. All these children underwent ICR with CPB. Demographic data, preoperative, intraoperative, and postoperative variables were compared between the study and the control groups.

Results Prevalence of severe vitD deficiency was 93.1\%. When compared with the control group, study group showed higher serum vitD levels in the immediate preoperative period $(p=0.001)$, postoperative period following CPB $(p=0.012)$, and on the first postoperative day $(p=0.003)$. No statistically significant difference was observed in postoperative mechanical ventilation $(p=0.35)$, intensive care unit (ICU) stay $(p=0.15)$, and inotropic duration $(p=0.19)$.

Conclusion Children with TOF are highly deficient of vitD, its level falls further after $\mathrm{CPB}$, and supplementing vitD preoperatively does not influence postoperative recovery pattern. Supplementation of vitD as "stoss therapy" was useful in raising the serum levels before and after cardiac surgery.
DOI https://doi.org/

$10.1055 / \mathrm{s}-0039-1696910$ ISSN 2457-0206.
Copyright $\odot 2020$ Official Publication of The Simulation

Society (TSS), accredited by International Society of Cardiovascular Ultrasound (ISCU). 


\section{Introduction}

Vitamin D (vitD) deficiency is now considered to be a common nutritional deficiency and one of the most common undiagnosed medical conditions. ${ }^{1}$ VitD can be synthesized in skin epithelial cells, but is not abundantly available in foodstuffs. VitD deficiency occurs as a result of a combination of poor intake and inadequate synthesis. Deficiency is defined as serum vitD level $<20 \mathrm{ng} / \mathrm{mL}$ ( $50 \mathrm{nmol} / \mathrm{L}) .{ }^{2}$ Various studies in India have shown the prevalence of vitD deficiency from 70 to $100 \%$. Studies from Delhi and Lucknow have revealed a prevalence of $93.7 \%$ and $78.3 \%$, respectively. ${ }^{3,4}$ Many studies have reported that vitD supplementation improves growth parameters of children. ${ }^{5}$

VitD deficiency is highly prevalent in pediatric population with congenital heart disease (CHD). ${ }^{6}$ The serum level of vitD decreases in these patients who undergo surgery with cardiopulmonary bypass (CPB). ${ }^{7}$ Postoperatively these patients suffer significant morbidities, which may include a pronounced systemic inflammatory response (SIR), respiratory failure, electrolyte disturbances, arrhythmias, myocardial dysfunction, kidney failure, infections, and endocrine disturbances. ${ }^{6-10}$ The role of vitD is recognized as a pleotropic hormone responsible for functioning of organ systems central to critical illness pathophysiology ${ }^{11,12}$ including electrolyte homeostasis, cardiovascular health, inflammation, and innate immunity. ${ }^{13-16}$ Available data from many studies suggest that most CHD patients are vitD deficient following cardiac surgery and the immediate postoperative serum levels are associated with the subsequent clinical course. ${ }^{17-20}$ Despite the known facts about vitD deficiency in children with CHD, very little or no work has been done in this subset of patients. We did not come across any prospective study on preoperative treatment of vitD deficiency on clinical outcomes after congenital cardiac surgery.

This study assessed the prevalence of vitD deficiency in children with tetralogy of Fallot (TOF) and whether preoperative vitD supplementation as "stoss therapy" can successfully treat perioperative vitD deficiency and cause improvement in postoperative convalescence of the pediatric cardiac surgical patients.

\section{Material and Methods}

The study was conducted at the Cardiothoracic and Vascular Surgery (CTVS) department of a tertiary care teaching hospital in Northern India. A total of 60 children aged between 6 months and 18 years diagnosed with congenital cyanotic heart disease (CCHD), TOF, who underwent intracardiac repair (ICR) with CPB were enrolled in this RCT. Children undergoing emergency surgery, those associated with other syndromes like Down's, Edward's, Noonan's, hypercalcinosis, and so forth, other CCHD patients other than TOF, those undergoing staged procedures like bidirectional Glenn, Fontan operations, and closed heart surgeries like Blalock-Taussig shunt were excluded.

Approval was obtained from the institutional ethics committee. Written and informed consent was obtained from the parents of all the participating children. This RCT is registered with clinical triials registration India (CTRI) with the no- CTRI/2017/12/010827. All the subjects were randomized into 2 groups, group A (control) 30 children and group B (study) 30 patients. Children in the study group were administered vitD orally.

VitD was available as sachets containing 60,000 international units (IU) of vitD in white granular powder form (Troika Pharmaceuticals Ltd., Ahmedabad, Gujarat, India). These powdered granules are lipophilic in nature and milk was used as vehicle to administer it for better bioavailability. VitD was administered as "stoss therapy," a single megadose therapy at 10,000 units $/ \mathrm{kg}$ body weight, up to the highest upper limit of 400,000 units. ${ }^{2,21,22}$

The patients were referred to CTVS department for elective surgery after comprehensive cardiac diagnosis by the cardiologist. Blood samples were drawn from these children for analyzing base line serum vitD level along with other routine biochemistry, hemogram, and urine samples were collected to estimate urinary calcium and creatinine. All those patients having vitD level $<20 \mathrm{ng} / \mathrm{dL}$ were enrolled in the study and randomized into two groups. Computer-generated random number table was utilized for randomization. Patients were randomized to either study group or control group (did not receive vitD supplementation). The study group patients were sent to the ICU, where calculated amount of vitD added in half cup of milk (50 mL) was given to the children orally under supervision of the allotted staff nurse and senior resident. They remained under observation for a further two hours in the ICU precinct for any adverse reactions like vomiting, fever, convulsion, and so forth. A date for elective surgery was given after 2 weeks \pm 1 week from the date of vitD administration to the children in study group and they were sent home, whereas the control group patients were operated at the same sitting depending on waiting list and date allocation by the surgeon. All the surgeries were performed by a single surgical team.

Samples were drawn at 4 time points. A baseline blood sample (sample A) collected at the first surgical outpatient department visit for assessing level of vitD deficiency. A second blood sample (sample B) was collected just before surgery which measured the vitD level (2-3 weeks post vitD supplementation).Third blood sample was drawn within 6 hours after surgery (sample $\mathrm{C}$ ) which estimated the serum vitD levels after CPB and the fourth blood sample was taken on the first postoperative day (sample D). Urine samples were collected to measure urinary calcium and creatinine levels at the same timings parallel to that of blood sample collection.

The blood levels were used to detect hypo/normo/hyper vitaminosis $\mathrm{D}$ and the urine levels of calcium and creatinine ratio were utilized to identify whether any toxicity is appearing. Kidney function tests; liver function tests; complete blood count; C-reactive protein (CRP); and culture and sensitivity of different body fluids like blood, respiratory secretions, and urine were evaluated as per the postoperative cardiac surgical protocol in our intensive care unit (ICU). Serum calcium and parathormone (PTH) were measured preoperatively before intervention and postoperatively on day 1 . Serum vitD and 
serum PTH were measured by chemiluminescence method (DiaSorin LIASON). Urinary calcium was measured using photometric Arsenazo method (Rochs) while urinary creatinine was measured using photometric Jaffe rate blanked method (Modular P). ICU protocols for the postoperative management of these patients were not interfered.

Primary outcomes of the study were immediate postoperative serum vitD levels which determine whether preoperative oral vitD supplementation in the study group compared with standard care in the control group results in a significant reduction in postoperative vitD deficiency in pediatric population with TOF. Secondary outcomes like postoperative duration of inotrope requirement, mechanical ventilation, ICU stay, infection rate, and vitD-related adverse effects, that is, hypercalcemia and hypercalciuria were assessed.

Statistical analysis of categorical variables was compared using Fischer test. Continuous variables were compared using nonparametric Mann-Whitney test and unpaired $t$-test with consideration of $95 \%$ confidence limit. Any p value $<0.05$ was considered as statistically significant. Statistical Analysis was performed using STATA 14 software (IBM, Chicago, IL, USA).

\section{Results}

All the 60 children in this present study had vitD deficiency. The serum vitD level of the population was $11.66 \pm 5.43 \mathrm{ng} / \mathrm{mL}$. Prevalence of severe vitD deficiency (serum vitD $<20 \mathrm{ng} / \mathrm{mL}$ ) was $93.1 \%$ and vitD insufficiency not amounting to severe deficiency (serum vitD $\geq 20$ and $<30 \mathrm{ng} / \mathrm{mL}$ ) was $6.9 \%$.

Among the categorical variables, male to female ratio was 2:1 in the control group and 3:2 in the study group $(p=0.122)$. There was no statistically significant difference in baseline characteristics (age, body weight, and length) and intraoperative variables (CPB and aortic cross clamp [ACC] duration) between the control and study groups as shown in - Table 1.

As described in - Table 2, the baseline serum vitD levels (sample A) of the study $(11.62 \pm 4.81 \mathrm{ng} / \mathrm{mL})$ and the control $(11.71 \pm 6.31 \mathrm{ng} / \mathrm{mL})$ groups were comparable $(p=0.895)$. After 2 weeks of vitD supplementation, its serum level (sample B) was significantly higher $(p=0.001)$ of the study group $(33.43 \pm 18.88 \mathrm{ng} / \mathrm{mL})$ than that of control group $(10.94 \pm 5.45 \mathrm{ng} / \mathrm{mL})$. The vitD level immediately after surgery (sample $\mathrm{C}$ ) was significantly higher $(p=0.012)$ of the study group $(24.48 \pm 12.74 \mathrm{ng} / \mathrm{mL})$ than that of the control group (12.11 $\pm 6.04 \mathrm{ng} / \mathrm{mL}$ ). The vitD level on the first postoperative day (sample $D)$ was significantly higher $(p=0.003)$ of the study group $(42.80 \pm 28.38 \mathrm{ng} / \mathrm{mL})$ than that of the control group $(10.38 \pm 5.23 \mathrm{ng} / \mathrm{mL})$. The change in serum vitD level between pre- and post CPB samples ( $B$ and $C$ ) was statistically significant $(p=0.006)$ between the study $(9.43 \pm 8.68 \mathrm{ng} / \mathrm{mL})$ and the control $(-1.56 \pm 2.69 \mathrm{ng} / \mathrm{mL})$ groups.

- Table 3 delineates the statistical difference of the serum vitD levels between the baseline sample (A) and other samples at various other time points $(B, C$, and $D)$ in the study group. Following vitD supplementation, it's blood levels increased to $33.43 \pm 18.88 \mathrm{ng} / \mathrm{mL}$ in sample B as compared with baseline sample A $11.62 \pm 4.81 \mathrm{ng} / \mathrm{mL}(\mathrm{p}=0.11)$. Following CPB in sample $C$, the levels were decreased to $24.48 \pm 12.74 \mathrm{ng} / \mathrm{mL}$ ( $p=0.07)$, which was still higher than the baseline value. On the first postoperative day sample (D), the vitD levels (42.80 \pm $28.38 \mathrm{ng} / \mathrm{mL}, p=0.08$ ) returned to a further higher level.

- Table 4 demonstrated the biochemical parameters of vitD toxicity in the pre (A) and post (D)operative period for

Table 1 Comparison of baseline characteristics and intraoperative variables of study and control groups

\begin{tabular}{|l|l|l|l|l|}
\hline SI. no. & Variable & $\begin{array}{l}\text { Control group } \\
\text { mean } \pm \text { SD }\end{array}$ & $\begin{array}{l}\text { Study group } \\
\text { mean } \pm \text { SD }\end{array}$ & $p$-Value \\
\hline 1 & Age $(\mathrm{y})$ & $6.52 \pm 3.55$ & $5.96 \pm 2.88$ & 0.5337 \\
\hline 2 & Weight $(\mathrm{kg})$ & $20.28 \pm 10.83$ & $19.32 \pm 8.94$ & 0.7277 \\
\hline 3 & Length $(\mathrm{cm})$ & $102.45 \pm 25.42$ & $96.64 \pm 20.48$ & 0.3646 \\
\hline 4 & CPB time (min) & $94.2 \pm 29.2$ & $98.1 \pm 31.5$ & 0.68 \\
\hline 5 & ACC time (min) & $57.2 \pm 21.8$ & $54.2 \pm 15.4$ & 0.61 \\
\hline
\end{tabular}

Abbreviations: ACC, aortic cross clamp; CPB, cardiopulmonary bypass.

Table 2 Comparison of the serum vitD levels between the control and study groups at different time points

\begin{tabular}{|l|l|l|l|l|l|}
\hline SI. no. & Variables & Samples & $\begin{array}{l}\text { Control group } \\
\text { mean } \pm \text { SD }\end{array}$ & $\begin{array}{l}\text { Study group } \\
\text { mean } \pm \text { SD }\end{array}$ & $p$-Value \\
\hline 1 & S. vitD $(\mathrm{ng} / \mathrm{mL})$ & A & $11.71 \pm 6.31$ & $11.62 \pm 4.81$ & 0.8953 \\
\hline 2 & S. vitD $(\mathrm{ng} / \mathrm{mL})$ & B & $10.94 \pm 5.45$ & $33.43 \pm 18.88$ & 0.0010 \\
\hline 3 & S. vitD $(\mathrm{ng} / \mathrm{mL})$ & C & $12.11 \pm 6.04$ & $24.48 \pm 12.74$ & 0.0129 \\
\hline 4 & S. vitD $(\mathrm{ng} / \mathrm{mL})$ & D & $10.38 \pm 5.23$ & $42.80 \pm 28.38$ & 0.0038 \\
\hline 5 & $\begin{array}{l}\text { Change in S. vitD } \\
\text { during CPB }\end{array}$ & B-C & $-1.56 \pm 2.69$ & $9.43 \pm 8.68$ & 0.0067 \\
\hline
\end{tabular}

Abbreviations: A, baseline blood sample; B, sample post vitD administration before surgery; C, sample post CPB; CPB, cardiopulmonary bypass; $D$, sample postoperative day $1 ; S$, serum. 
Table 3 Statistical difference of the serum vitD levels between the baseline sample $(A)$ and other samples at various other time points $(B, C, D)$ in the study group

\begin{tabular}{|l|l|l|l|}
\hline Sl. no. & Samples & Serum vitD $(\mathrm{ng} / \mathrm{mL})$, mean \pm SD, study group & $p$-Value \\
\hline 1 & A & $11.62 \pm 4.81$ & - \\
\hline 2 & B & $33.43 \pm 18.88$ & 0.11 \\
\hline 3 & C & $24.48 \pm 12.74$ & 0.07 \\
\hline 4 & D & $42.80 \pm 28.38$ & 0.08 \\
\hline
\end{tabular}

Abbreviations: A, baseline blood sample; B, sample post vitD administration before surgery; C, post CPB blood sample; $D$, sample postoperative day 1 .

Table 4 Comparison of the laboratory parameters pertaining to vitamin D toxicity between the control and study groups during the perioperative period

\begin{tabular}{|l|l|l|l|l|l|}
\hline SI. no. & Variable & Sample & $\begin{array}{l}\text { Control group } \\
\text { Mean } \pm \text { S.D }\end{array}$ & $\begin{array}{l}\text { Study group } \\
\text { Mean } \pm \text { S.D }\end{array}$ & $p$-Value \\
\hline 1 & Urinary calcium/creatinine ratio & D & $2.01 \pm 1.69$ & $1.11 \pm 0.77$ & 0.157 \\
\hline 2 & Serum PTH $(\mathrm{pg} / \mathrm{mL})$ & D & $48.13 \pm 37.39$ & $40.7 \pm 11.57$ & 0.9648 \\
\hline 3 & Serum Ca $(\mathrm{mg} / \mathrm{dL})$ & A & $7.83 \pm 0.44$ & $7.80 \pm .36$ & 0.4101 \\
\hline 4 & Serum Ca $(\mathrm{mg} / \mathrm{dL})$ & D & $8.72 \pm 0.91$ & $8.98 \pm 0.80$ & 0.3137 \\
\hline
\end{tabular}

Abbreviations: A, baseline blood sample; Ca, Calcium; D, sample postoperative day 1; PTH, parathormone.

Table 5 Comparison of the postoperative variables between the control and study groups

\begin{tabular}{|l|l|l|l|l|}
\hline SI. no. & Variables & $\begin{array}{l}\text { Control group } \\
\text { mean } \pm \text { SD }\end{array}$ & $\begin{array}{l}\text { Study group } \\
\text { mean } \pm \text { SD }\end{array}$ & $p$-Value \\
\hline 1 & Inotrope duration (h) & $55.16 \pm 23.87$ & $47.76 \pm 27.13$ & 0.19 \\
\hline 2 & Ventilation duration (h) & $26.74 \pm 15.79$ & $22.4 \pm 15.81$ & 0.36 \\
\hline 3 & ICU stay duration (h) & $65.37 \pm 19.59$ & $54 \pm 26.06$ & 0.16 \\
\hline
\end{tabular}

Abbreviations: ICU, intensive care unit; ventilation.

serum calcium and only postoperative values (sample D) for serum PTH and urinary calcium/creatinine ratio. The serum PTH levels were lower in the study group $(40.7 \pm 11.57 \mathrm{pg} / \mathrm{mL})$ as compared with the control group $(48.13 \pm 37.39 \mathrm{pg} / \mathrm{mL})$. The urinary calcium creatinine ratio was lower in the study group (1.11 \pm 0.77$)$ as compared with the control group (2.01 \pm 1.69 ). However, these were statistically insignificant. The serum calcium levels were lower in the control than in the study group at both pre and postoperative period, but without having any statistical difference.

- Table 5 describes the postoperative parameters during convalescence after surgery. There was no statistically significant difference between the two groups with respect to duration of inotropic requirement ( $p=0.19$ ), mechanical ventilation $(p=0.36)$, and ICU stay $(p-0.16)$ in the postoperative period.

Four patients from the study group and six children from the control group developed low cardiac output syndrome in the early postoperative period but all of them recovered. Three patients from group A and two from group B manifested junctional ectopic tachycardia and were treated. We didn't have any neurological deficit or death in this study population.

\section{Discussion}

In the present study, the prevalence of vitD deficiency was $100 \%$. Similar findings were noted by many authors from various studies previously. A study which included a subgroup of 122 CHD patients reported that 7 out of 10 critically ill children were vitD deficient and subgroup analysis in postoperative CHD children confirmed a 73\% deficiency rate. ${ }^{23}$ Khadgawat et al and Garg et al have also reported a high prevalence of vitamin D deficiency in Indian population. ${ }^{24,25}$

Misra et al adopted stoss therapy for vitD supplementation and found it successful in patients from far off places and belonging to low socioeconomic strata in whom regular follow-up is a major concern for the treatment of vitD deficiency rickets at a dose of 100,000 to 600,000 IU of vitD orally over a period of 1 to 5 days followed by 400 to 1,000 IU of vitD daily or $50,000 \mathrm{IU}$ of vitD weekly for 8 weeks. ${ }^{26}$ As patients in our study also belong to a similar socioeconomic class and come from faraway places from all over the country, we have also adopted single mega dose (stoss therapy) regimen for vitD supplementation. Modified stoss therapy in which 60,000 IU of oral cholecalciferol was given daily for 10 days was tried by Sethuraman et al in our institution which gave promising results in severe clinical rickets and congenital ichthyosis. ${ }^{27}$ In the present study, we supplemented single megadose oral vitD at $10,000 \mathrm{IU} / \mathrm{kg}, 2 \pm 1$ weeks prior to elective ICR in pediatric CCHD patients with TOF. Sheperd et al in a retrospective review, identified the role of administering stoss therapy for effectively treating severe vitD deficiency in cystic fibrosis children. ${ }^{28}$ 
Studies in adult CHD patients highlight that maintaining optimum serum vitD levels in the perioperative period decreases inflammatory reactions, increases myocardial function, ${ }^{12,17-20,29-32}$ and decreases the incidence of nosocomial infections by upregulating the production of endogenous antimicrobial peptides called cathelicidins. ${ }^{33-35}$ Lee et al in their observational study of critically ill patients predicted higher mortality rates up to $45 \%$ in patients with vitD deficiency. ${ }^{12}$ In many other series, mortality in critically ill pediatric population as a result of vitD deficiency ranges from 35 to $70 \% .^{23,36,37}$ Tishkoff et al by means of their animal experiments demonstrated that vitD has an important role in the cardiac diastolic function by a mechanism dependent on calcium concentrations in the sarcoplasmic reticulum in the cell. ${ }^{38}$ We in our study did not find differences in terms of cardiac function and mortality in either group even if all the children in the study were severely deficient of vitD.

We in our study had a rise in the serum vitD levels among the study group in the immediate preoperative period. We observed a significant increase in serum vitD levels on first postoperative day in children receiving vitD supplementation after an initial fall in serum vitD levels in the immediate postoperative period as a result of CPB effect. Many other studies also showed significant decrease in serum vitD levels as a result of CPB effect in the immediate postoperative period. On the contrary, the control group showed rise in the mean value of serum vitD levels in the immediate post CPB period in sample C compared with sample B. Riad et $\mathrm{al}^{39}$ McNally et al, ${ }^{40}$ Graham et $a l,{ }^{41}$ and Krishnan et al ${ }^{42}$ studied the effect of CPB on serum vitamin D levels which is compared in - Table 6 .

McNally et al observed vitD in the ultrafiltrate of patients in whom modified ultrafiltration was performed, suggesting that a mechanism other than CPB dilution effect may be responsible for postoperative drop in serum vitD levels. ${ }^{40}$ Krishnan et al observed a reduction of 35\% in total vitD post CPB in adults. ${ }^{42}$ They attributed this reduction to hemodilution secondary to acute fluid shifts. They also speculated that vitD-binding protein adhered to the walls of plastic tubes, thus accounting for some reduction in serum vitD levels.
Graham et $\mathrm{al}^{41}$ in their study observed that CPB did not have any effect on serum vitD levels in neonates postcardiac surgery and $84 \%$ of children have vitD deficiency from preoperative period itself. In our study, the control group followed the same pattern as shown by Graham et $\mathrm{al}^{41}$ whereas the study group followed the pattern found in the studies published by others like Riad Abou et al, ${ }^{39} \mathrm{McNally}$ et $\mathrm{al},{ }^{40}$ and Krishnan et al. ${ }^{42}$

One interesting finding was noticed in - Table 6 the presurgery vitD levels of the Graham et $\mathrm{al}^{41}$ study and the control group of our study corresponded to severe vitD deficiency, and their post CPB levels increased (though statistically insignificant) instead of decreasing contray to the findings from other three studies plus children in our study group where post CPB vitD level decreased significantly. Even though we cannot reach any conclusion as to why the serum vitD levels behave differently to $\mathrm{CPB}$ and acute hemodilution at different body levels of deficiency, we propose that it could be related to the multiple factors that control the serum vitD levels such as serum PTH, fibroblast growth factor (FGF) 23 levels, calcium levels, the distribution between the free and bound vitD levels in serum, and so forth.

In sample D there was an overshoot of serum vitD levels in the study group which was not observed in the control group. The mechanism of the delayed rise is unclear. Most likely explanation is the enzyme induction by PTH. The rise in PTH following CPB may be significant in the study group. It is likely that the initial rise in PTH was accompanied by a delayed rise in serum vitD. ${ }^{42}$

A recent randomized placebo control trial by Shedeed et al of vitD supplementation in 80 infants with congestive heart failure was reported in which infants receiving vitD supplementation had greater improvements in clinical symptoms and echocardiographic measurements of ventricular size and function. ${ }^{43}$ Shedeed et al, ${ }^{43}$ McNally et al, ${ }^{40}$ and Graham et al ${ }^{41}$ noticed a reduced requirement of ionotropic support, fluid requirements, and short duration of mechanical ventilation among those with a higher serum vitD levels postoperatively. On the contrary, Lucidarme et $\mathrm{al}^{18}$ and Rippel et $\mathrm{al}^{37}$ did not find any correlation between serum vitD levels and the various prognostic outcomes. In our study we didn't find a

Table 6 Comparison of various studies showing the effect of CPB on serum Vitamin D levels

\begin{tabular}{|c|c|c|c|c|c|c|}
\hline & $\begin{array}{l}\text { Riad Abou et } \text { al }^{39} \\
\text { (CHD) }\end{array}$ & $\begin{array}{l}\text { McNaly et a }{ }^{40} \\
(\mathrm{CHD})\end{array}$ & $\begin{array}{l}\text { Graham et } \mathrm{al}^{41} \\
\text { (CHD) }\end{array}$ & $\begin{array}{l}\text { Krishnan et } \mathrm{al}^{42} \\
\text { (CHD) }\end{array}$ & $\begin{array}{l}\text { Current } \\
\text { study- } \\
\text { study group }\end{array}$ & $\begin{array}{l}\text { Current } \\
\text { study- } \\
\text { control group }\end{array}$ \\
\hline Sample size (n) & 20 & 58 & 76 & 19 & 30 & 30 \\
\hline Age range & 2 months -17 years & $\begin{array}{l}2 \text { months-5 } \\
\text { years }\end{array}$ & Neonates & $>18$ years adult & $\begin{array}{l}6 \text { months-18 } \\
\text { years }\end{array}$ & $\begin{array}{l}6 \text { months-18 } \\
\text { years }\end{array}$ \\
\hline \multicolumn{7}{|l|}{$\begin{array}{l}\text { Vitamin D level } \\
(\mathrm{ng} / \mathrm{mL})\end{array}$} \\
\hline Presurgery & 21.3 & 23.3 & 14.4 & 23.6 & 33.43 & 10.94 \\
\hline Post CPB & 19.5 & 13.7 & 17.0 & 15.2 & 24.48 & 12.11 \\
\hline $\begin{array}{l}\text { First postopera- } \\
\text { tive day }\end{array}$ & & & 14.1 & & 42.80 & 10.39 \\
\hline
\end{tabular}

Abbreviation: CHD, congenital heart disease. 
statistically significant improvement in terms of postoperative inotropic requirement, ventilation duration, and length of ICU stay between the two groups.

\section{Limitations of the Study}

Since we could study a less number (60) of patients, the results need further verification with larger sample size RCT. There is lack of information on long-term effects on vitD status, as we did not measure vitD levels beyond the first postoperative day. In our study the reason for the rise of serum vitD levels in the immediate post CPB period in the control group could not be explained well. Free vitD could have been calculated to confirm fall in level as $99 \%$ of vitD is carrier protein bound. Free vitD is lost in mudified ultrafiltration and hemodilution during $\mathrm{CPB} .{ }^{44}$ Serum albumin levels should have been measured and correlated. ${ }^{42}$ To assess the effect of vitD supplementation on cardiac function, parameters like cardiac index should have been measured, which was not done in this study.

\section{Conclusion}

The present study concluded that serum vitD level was severely low in CCHD children with TOF and also the vitD level further decreased after ICR with CPB. Preoperative vitD supplementation as single megadose "stoss therapy" can treat this severe deficiency and can also handle the further decrease in serum vitD levels in the immediate postoperative period due to the effect of CPB. But it did not show any beneficial effect with respect to postoperative convalescence in terms of either decrease in inotropic requirement, mechanical ventilation, and ICU stay duration.

\section{Fundings}

Funds were availed from the institute intramural fund to conduct this study.

\section{Conflict of Interest}

The authors state that they do not have any conflict of interest.

\section{References}

1 Holick MF. Vitamin D: extraskeletal health. Rheum Dis Clin North Am 2012;38(1):141-160

2 Holick MF, Binkley NC, Bischoff-Ferrari HA, et al. Endocrine Society. Evaluation, treatment, and prevention of vitamin D deficiency: an Endocrine Society clinical practice guideline. J Clin Endocrinol Metab 2011;96(7):1911-1930

3 Marwaha RK, Tandon N, Agarwal N, et al. Impact of two regimens of vitamin D supplementation on calcium-vitamin D-PTH axis of schoolgirls of Delhi. Indian Pediatr 2010;47(9):761-769

4 Arya V, Bhambri R, Godbole MM, Mithal A. Vitamin D status and its relationship with bone mineral density in healthy Asian Indians. Osteoporos Int 2004;15(1):56-61

5 Rao Y, Midha T, Tripathi P, Singh S, Sharma RD, Arora S. Effect of vitamin D supplementation on growth parameters in children with Vitamin D deficiency. Journal of Pediatric Sciences. 2016;8:e263

6 Dyke PC, II. Yates AR, Cua CL, et al. Increased calcium supplementation is associated with morbidity and mortality in the infant postoperative cardiac patient. Pediatr Crit Care Med 2007;8(3):254-257

7 McNally JD, O'Hearn K, Lawson ML, et al. Canadian Critical Care Trials Groups. Prevention of vitamin D deficiency in children following cardiac surgery: study protocol for a randomized controlled trial. Trials 2015;16:402 10.1186/ s13063-015-0922-8

8 Brix-Christensen V. The systemic inflammatory response after cardiac surgery with cardiopulmonary bypass in children. Acta Anaesthesiol Scand 2001;45(6):671-679

9 Gazit AZ, Huddleston CB, Checchia PA, Fehr J, Pezzella AT. Care of the pediatric cardiac surgery patient-part 1 . Curr Probl Surg 2010;47(3):185-250

10 McEwan A. Aspects of bleeding after cardiac surgery in children. Paediatr Anaesth 2007;17(12):1126-1133

11 Lee P. Vitamin D metabolism and deficiency in critical illness. Best Pract Res Clin Endocrinol Metab 2011;25(5):769-781

12 Lee P, Eisman JA, Center JR. Vitamin D deficiency in critically ill patients. N Engl J Med 2009;360(18):1912-1914

13 Amrein K, Venkatesh B. Vitamin D and the critically ill patient. Curr Opin Clin Nutr Metab Care 2012;15(2):188-193

14 Baeke F, Gysemans C, Korf H, Mathieu C. Vitamin D insufficiency: implications for the immune system. Pediatr Nephrol 2010;25(9):1597-1606

15 Rigby WF, Denome S, Fanger MW. Regulation of lymphokine production and human $\mathrm{T}$ lymphocyte activation by 1,25-dihydroxyvitamin D3. Specific inhibition at the level of messenger RNA. J Clin Invest 1987;79(6):1659-1664

16 Bhalla AK, Amento EP, Serog B, Glimcher LH. 1,25-Dihydroxyvitamin D3 inhibits antigen-induced T cell activation. J Immunol 1984;133(4):1748-1754

17 Braun AB, Gibbons FK, Litonjua AA, Giovannucci E, Christopher KB. Low serum 25-hydroxyvitamin D at critical care initiation is associated with increased mortality. Crit Care Med 2012;40(1):63-72

18 Lucidarme O, Messai E, Mazzoni T, Arcade M, du Cheyron D. Incidence and risk factors of vitamin D deficiency in critically ill patients: results from a prospective observational study. Intensive Care Med 2010;36(9):1609-1611

19 McKinney JD, Bailey BA, Garrett LH, Peiris P, Manning T, Peiris AN. Relationship between vitamin D status and ICU outcomes in veterans. J Am Med Dir Assoc 2011;12(3):208-211

20 Higgins DM, Wischmeyer PE, Queensland KM, Sillau SH, Sufit AJ, Heyland DK. Relationship of vitamin D deficiency to clinical outcomes in critically ill patients. JPEN J Parenter Enteral Nutr 2012;36(6):713-720

21 McNally JD, Iliriani K, Pojsupap S, et al. Rapid normalization of vitamin D levels: a meta-analysis. Pediatrics 2015;135(1):e152-e166

22 Koçyiğit C, Çatlı G, İnce G, Özkan EB, Dündar BN. Can stoss therapy be used in children with Vitamin D deficiency or insufficiency without rickets? J Clin Res Pediatr Endocrinol 2017;9(2):150-155

23 McNally JD, Menon K, Chakraborty P, et al. Canadian Critical Care Trials Group. The association of vitamin D status with pediatric critical illness. Pediatrics 2012;130(3):429-436

24 Khadgawat R, Thomas T, Gahlot M, et al. The effect of puberty on interaction between Vitamin D status and insulin resistance in obese Asian-Indian children. Int J Endocrinol 2012;2012:173581

25 Garg MK, Marwaha RK, Khadgawat R, et al. Efficacy of vitamin D loading doses on serum 25-hydroxy vitamin D 
levels in school going adolescents: an open label non-randomized prospective trial. J Pediatr Endocrinol Metab 2013;26(5-6):515-523

26 Misra M, Pacaud D, Petryk A, Collett-Solberg PF, Kappy M; Drug and Therapeutics Committee of the Lawson Wilkins Pediatric Endocrine Society. Vitamin D deficiency in children and its management: review of current knowledge and recommendations. Pediatrics 2008;122(2):398-417

27 Sethuraman G, Marwaha RK, Challa A, et al. Vitamin D: a new promising therapy for congenital ichthyosis. Pediatrics 2016;137(1):1-5

28 Shepherd D, Belessis Y, Katz T, Morton J, Field P, Jaffe A. Single high-dose oral vitamin D3 (stoss) therapy-a solution to vitamin D deficiency in children with cystic fibrosis? J Cyst Fibros 2013;12(2):177-182

29 Braun A, Chang D, Mahadevappa K, et al. Association of low serum 25-hydroxyvitamin D levels and mortality in the critically ill. Crit Care Med 2011;39(4):671-677

30 Matthews LR, Ahmed Y, Wilson KL, Griggs DD, Danner OK. Worsening severity of vitamin D deficiency is associated with increased length of stay, surgical intensive care unit cost, and mortality rate in surgical intensive care unit patients. Am J Surg 2012;204(1):37-43

31 Zittermann A, Schleithoff SS, Götting C, et al. Calcitriol deficiency and 1-year mortality in cardiac transplant recipients. Transplantation 2009;87(1):118-124

32 Börgermann J, Lazouski K, Kuhn J, et al. 1,25-Dihydroxyvitamin D fluctuations in cardiac surgery are related to age and clinical outcome. Crit Care Med 2012;40(7):2073-2081

33 Hata TR, Kotol P, Jackson M, et al. Administration of oral vitamin $D$ induces cathelicidin production in atopic individuals. J Allergy Clin Immunol 2008;122(4):829-831

34 Gombart AF, Borregaard N, Koeffler HP. Human cathelicidin antimicrobial peptide (CAMP) gene is a direct target of the vitamin D receptor and is strongly up-regulated in myeloid cells by 1,25-dihydroxyvitamin D3. FASEB J 2005;19(9):1067-1077

35 Jeng L, Yamshchikov AV, Judd SE, et al. Alterations in vitamin D status and anti-microbial peptide levels in patients in the intensive care unit with sepsis. J Transl Med 2009;7:28

36 Madden K, Feldman HA, Smith EM, et al. Vitamin D deficiency in critically ill children. Pediatrics 2012;130(3):421-428

37 Rippel C, South M, Butt WW, Shekerdemian LS. Vitamin D status in critically ill children. Intensive Care Med 2012;38(12):2055-2062

38 Tishkoff DX, Nibbelink KA, Holmberg KH, Dandu L, Simpson $\mathrm{RU}$. Functional vitamin $\mathrm{D}$ receptor (VDR) in the t-tubules of cardiac myocytes: VDR knockout cardiomyocyte contractility. Endocrinology 2008;149(2):558-564

39 Abou Zahr R, Faustino EVS, Carpenter T, et al. Vitamin D status after cardiopulmonary bypass in children with congenital heart disease. J Intensive Care Med 2017;32(8):508-513

40 McNally JD, Menon K, Chakraborty P, et al. Impact of anesthesia and surgery for congenital heart disease on the vitamin D status of infants and children: a prospective longitudinal study. Anesthesiology 2013;119(1):71-80

41 Graham EM, Taylor SN, Zyblewski SC, et al. Vitamin D status in neonates undergoing cardiac operations: relationship to cardiopulmonary bypass and association with outcomes. J Pediatr 2013;162(4):823-826

42 Krishnan A, Ochola J, Mundy J, et al. Acute fluid shifts influence the assessment of serum vitamin D status in critically ill patients. Crit Care 2010;14(6):R216

43 Shedeed SA. Vitamin D supplementation in infants with chronic congestive heart failure. Pediatr Cardiol 2012;33(5):713-719

44 Bikle DD, Gee E, Halloran B, Kowalski MA, Ryzen E, Haddad JG. Assessment of the free fraction of 25-hydroxyvitamin D in serum and its regulation by albumin and the vitamin D-binding protein. J Clin Endocrinol Metab 1986;63(4):954-959 